\title{
"Santa Fe mo (inche ñi mapu mo cay)". Vida familiar en la reducción fronteriza de Santa Fe, Chile (Siglo XVIII)
}

\section{'Santa Fe mo (inche ñi mapu mo cay)' family life within the frontier settlement of Santa Fe, Chile (18th Century)}

\author{
Ignacio Chuecas Saldías ${ }^{1}$
}

\section{Resumen}

Este artículo explora aspectos característicos en la conformación y articulación de las familias mapuche asentadas en la reducción fronteriza de Santa Fe (Chile) durante el siglo XVIII. Santa Fe, al igual que el resto de las reducciones emplazadas a orillas del río Biobío, representaba un espacio negociado donde las familias indígenas, que en ella residieron, desplegaron estrategias de naturaleza híbrida a fin de conservar y acrecentar su capacidad de agencia al interior del sistema colonial hispano. Entre estas estrategias resulta posible considerar los peculiares sistemas de asentamiento, las prácticas matrimoniales, la función desempeñada por los caciques gobernadores y las nociones relativas a la propiedad y ocupación del espacio.

Palabras claves: reducciones, familias mapuche, siglo XVIII, frontera.

\begin{abstract}
This article explores some characteristic aspects in shaping and articulation of the Mapuche families settled within the frontier town of Santa Fe (Chile) during the eighteenth century. Santa Fe, like the rest of the reducciones situated on the banks of the Biobio River, represented a negotiated space where indigenous families deployed strategies hybrid nature to preserve and enhance their agency within the Spanish colonial system. Among these strategies we do find the peculiar settlement systems, marriage practices, the role played by the caciques governors and notions concerning ownership and occupation of space.
\end{abstract}

Keywords: Indian Settlements, Mapuche families, 18th century, Frontier.

Recibido: 11 abril 2016. Aceptado: 11 agosto 2017

1 Instituto de Historia, Pontificia Universidad Católica de Valparaíso. Paseo Valle 396, Viña del Mar, CHILE. Email: ichuecas@uc.cl 
Al publicar, en 1765, su obra Gramática de la Lengua Chilena el jesuita Andrés Febrés incluye en ella un curioso diálogo (Dugulun) entre el cacique gobernador de la reducción de Santa Fe, Ignacio Levihueque, y el cacique "itinerante" Pedro Llancahueno (Febrés, 1765, pp. 99-145). En aquel texto, evidentemente ficticio, ${ }^{2}$ el cacique santafesino hablando de sí mismo explica a Llancahueno: "Santa Fe mo (inche ñi mapu mo cay)". Frase que Febrés traduce como "En Santa Fe (es a saber mi tierra)". Sobre aquel espacio, que "es a saber mi tierra", versa el presente artículo, el cual pretende hacer un aporte a un tema largamente ignorado en la historiografía nacional: el modus vivendi y la articulación de familias mapuche en las reducciones fronterizas chilenas durante el período colonial. ${ }^{3}$

El análisis se focaliza, particularmente, en el estudio de esta reducción en su calidad de única población mapuche "oficialmente" reconocida por la administración colonial hispana en el territorio de la Isla de la Laja durante el siglo XVIII. Santa Fe representa, en efecto, un asentamiento de larga data (sus orígenes se pueden rastrear hacia inicios del siglo XVII), pero que experimentó importantes mutaciones, hasta su disolución en la década de $1830 .{ }^{4} \mathrm{Al}$ igual

2 Si bien ambos caracteres están inspirados en individuos históricos: Ignacio Levihueque, cacique de la reducción de Santa Fe al menos entre 1759 y 1784, y Pedro Llancahueno, mencionado en el Parlamento de Nacimiento (1764), "[...] con tal fortuna que el principal Governador Don Pedro Llancagueno, Yndio de conducta, y mui afecto a nosotros, no hizo la menor oposición [...]". Zavala, 2015, p. 276.

3 La etnohistoria chilena se ha interesado muy poco en las reducciones fronterizas del período colonial. El trabajo quizás más pertinente, pero con un enfoque altamente ahistórico y desvinculado de cualquier espacio concreto, característico de ciertas vertientes de la llamada Escuela de Estudios Fronterizos, es Ruiz-Esquide, 1993.

4 El 3 de febrero de 1618, en carta de Luis de Valdivia al general Vitelleschi, se hace alusión "a Cayancura, cacique de Santa Fe". Cf. Carta de Luis de Valdivia al general Muzio Vitelleschi, 1618, ARCJ, Chile, vol. 4, 57-63. Mocetones de esta reducción figuran, el 24 de febrero de 1647, entre los indios amigos que asistieron a las Paces de Quilín. Cf. Cartas del gobernador Martín de Mujica, 1647, AGI, Chile, vol. 21, sin foliar. La disolución definitiva de la reducción se consagró con la venta masiva de sus tierras a Francisco Bulnes Prieto efectuada mayoritariamente el año 1833. Cf. ANH, que el resto de las reducciones fronterizas, constituía un organismo híbrido entre "pueblo de indios", al modo de los emplazados en la zona central del país, y una "parcialidad", al modo de las agrupaciones indígenas de la "tierra adentro". En este contexto, el presente artículo busca incursionar en tres aspectos relacionados con la conformación de las familias que habitaban la reducción: (1) el tipo de organización familiar, (2) la constitución de una jerarquía en el gobierno de la reducción y (3) el acceso de las familias "reducidas" al uso de la tierra.

\section{Una reducción fronteriza chilena}

Durante el siglo XVIII chileno existieron cuatro reducciones en la ribera norte del Biobío, frontera de la "tierra adentro": Mocha, San Cristóbal, Talcamávida y Santa Fe (ver Figura 1). Siempre de "esta banda", en tierras de españoles, y siempre junto a un fuerte situado "de la otra banda" en la tierra adentro.

Como he afirmado, estos asentamientos coloniales representan híbridos entre pueblo de indios, al modo del Chile central, y una parcialidad al modo de "tierra adentro". Su función consistió en complementar la existencia de los fuertes que resguardaban la raya del Biobío, de tal modo que sus habitantes, considerados "indios amigos" por la administración colonial, sirvieran de auxiliares en los enfrentamientos bélicos y de mano de obra en los trabajos requeridos por su Majestad y la élite fronteriza (Ruiz-Esquide, 1993). Así como los fuertes eran considerados una "avanzada" en territorio exento a la administración imperial, el emplazamiento de estas reducciones en

NLA, vol. 2: 277, 279, 281, 283, 286, 288, 290, 292, 294, 296, 298, 300, 302, 304, 306, 312, 308, 310, 285 , $314,322,358,361,370,393,395$ у 396.

5 Se trata de los fuertes de San Pedro, Santa Juana y Nacimiento. El fuerte de San Carlos de Austria de Yumbel, asociado a la reducción de San Cristóbal, es el único que en el siglo XVIII no se encuentra al sur del Biobío, sino en pleno partido de Buena Esperanza de Rere. Durante la primera mitad del siglo XVII, la plaza de Yumbel se encontraba emplazada no lejos de la actual ciudad de Los Ángeles, en un sitio denominado más tarde "Yumbel el viejo", lugar donde se efectuó el Parlamento de Lonquilmo en 1784. Al mismo tiempo, paulatinamente, durante el siglo XVIII una parte de los habitantes de Talcamávida se asentaría en la ribera opuesta del Biobío junto al fuerte de Santa Juana. 


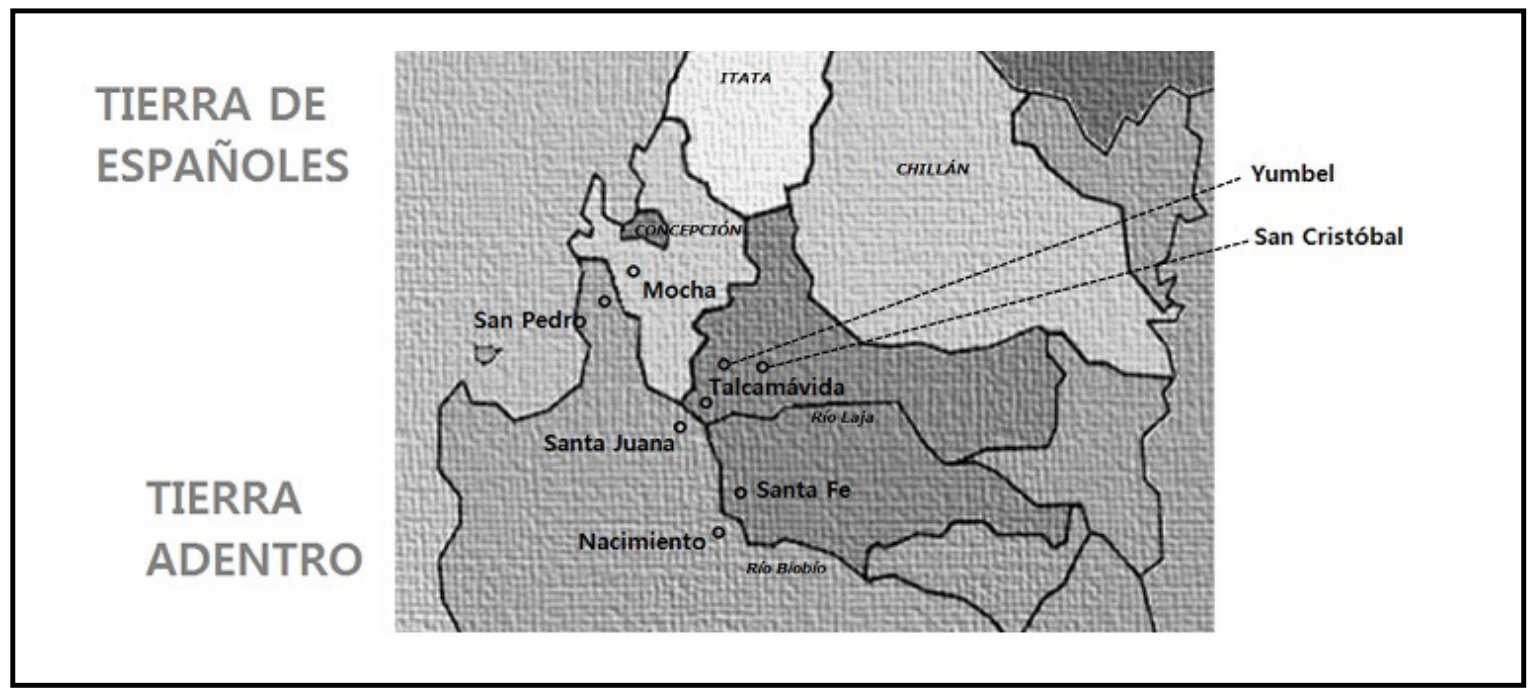

Figura 1. Reducciones fronterizas chilenas (siglo XVIII).

Fuente: Correspondencia del presidente Ambrosio Benavides, 1784-1785, AGI, Chile, vol. 193: sin foliar; Relación de las misiones de Chile y su frontera, 1784, ANH, Jesuitas, vol. 64, pieza 94: 197-233v.

"tierras de españoles" debía asegurar su asimilación al sistema colonial y evitar el peligro de infección con el admapu y los ánimos levantiscos y barbáricos vigentes en la tierra. ${ }^{6}$

En esta línea, Santa Fe gozará siempre de un estatus particular, junto con las otras reducciones fronterizas. En cierta medida se observa una suerte de condescendencia inicial por parte de la administración colonial, a fin de asegurar la permanencia de la población, que con el tiempo da paso a un mayor control. En general la documentación disponible suele referir a situaciones de control y descontrol en el seno de estas entidades. Ellas son producto del compromiso híbrido, representado por un estatuto negociado.

En relación a la vida de las familias en ellas radicadas, se ha de subrayar la fluidez de los patrones de asentamiento. Se trata de un fenómeno subyacente a la idea colonial de "reducir" y a los patrones tradicionales de asentamiento en el mundo prehispánico, caracterizados por la movilidad de residencia (Wright, 2003; Obregón Iturra, 2010, pp.

6 Sobre la noción de Admapu durante el siglo XVIII se puede consultar: Informe para instruir a Carlos III sobre el estado de las misiones, 1784, AOSF, Chillán Asuntos Varios (1782-1786), vol. 5, pieza 55.
184-186). Si bien la administración española suele reconocer en este espacio etnias trashumantes (pehuenches, por ejemplo), es evidente la intención de forzar la residencia en un espacio acotado (Villalobos, 1989). En este sentido se ha de considerar el fenómeno de reducción como parte característica de una estrategia colonial. A las trashumancias inherentes al modo de habitar indígena se suma, en el caso de esta zona en cuestión, el elemento del conflicto fronterizo con su consecuente inestabilidad poblacional. En tercer lugar, particularmente en los períodos en que se atenúa el conflicto bélico, se ha de considerar la movilidad propia de la vida fronteriza: trabajadores ocasionales, expediciones de comercio, razias menores, etcétera. (Lucaioli, 2010). En este horizonte, la reducción de Santa Fe se constituirá en una pieza fundamental como enclave del tránsito hacia y desde la tierra adentro. ${ }^{7}$

7 El año de 1724 una partida pehuenche ha traspasado el río Laja, para comerciar en las haciendas de la zona de Diguillín-Palpal en la esquina sur del partido de Chillán, llevando un salvoconducto "para que puedan pasar por cualquier parte adonde quisieren sin que nadie les embaracen" proporcionado por el cacique de Santa Fe. Cf. Sobre averiguar el paso de indios pehuenches a la Isla de Laja, 1724, ANH, CG, vol. 508, pieza 39, 239-244v. Este episodio evidencia la función ejercida por la reducción en el tránsito de individuos provenientes de los espacios extracoloniales. 


\section{Santa Fe hacia 1785}

El 5 de junio de 1785 el gobernador Ambrosio Benavides (1780-1787) redacta un informe describiendo el estado de las reducciones de la frontera. ${ }^{8}$ Se trata de un documento inédito en su forma, porque no se encuentran muchos de su tipo, a pesar de que corresponde muy bien a las iniciativas características de la administración borbónica en la segunda mitad del siglo XVIII, destinadas a proporcionar a la autoridad peninsular mayor información sobre la población americana. ${ }^{9}$ En este documento, el gobernador describe, a través de 17 puntos, la situación de las reducciones fronterizas chilenas, ocupando como modelo la reducción de San Cristóbal situada a unas seis leguas de la plaza de Yumbel, la cual es descrita en primer lugar y con datos pormenorizados, para continuar luego con el resto, ocupando Santa Fe el segundo lugar. Teniendo esto en mente, podemos focalizarnos en la descripción del estado de la reducción hacia 1785 .

Según Ambrosio Benavides, y sus informantes, Santa Fe "se halla situada en la misma provincia de Rere al norte del río Biobío, o dentro de los límites de la gobernación española, distante legua y media de la plaza de Nacimiento". ${ }^{10}$ Su territorio comprende una extensión de ocho mil cuadras (equivalentes a unas 12 mil hectáreas) y habría sido fundada en 1727 "por disposición de junta real de Hacienda, a cargo de los exjesuitas". ${ }^{11}$

8 Correspondencia del presidente Ambrosio Benavides, 1784-1785, AGI, Chile, vol. 193, sin foliar.

9 Es evidente la interdependencia que existe entre el informe sobre las misiones redactado por el obispo de la Concepción Francisco José Marán (1784) y el texto del informe del gobernador Benavides (1785), en particular en cuanto a los datos que figuran en las matrículas de las reducciones fronterizas. Por otra parte, a partir de la comparación de ambos textos, se evidencia el pesimismo y prejuicios con que el prelado de la diócesis penquista evalúa la realidad social y religiosa de los habitantes de dichas reducciones.

10 Correspondencia del presidente Ambrosio Benavides, 1784-1785, AGI, Chile, vol. 193, sin foliar. Nótese el término "gobernación española" para hacer referencia al espacio en el cual se encuentra la reducción. En otros textos contemporáneos aparece la fórmula "tierras de españoles" para hacer referencia a dicho espacio.

11 Correspondencia del presidente Benavides, 1784-85, AGI, Chile, vol. 193. Aquí se trata de la fundación de la misión jesuita (bastante tardía) y no de la reducción,
El emplazamiento de la reducción, en la esquina sur-poniente de la Isla de la Laja, se observa claramente en el mapa del "poncho chileno" publicado en 1777 (López, [1777] 1923). En esta representación un tanto imperfecta de la frontera, Santa Fe figura junto a la ribera norte del Biobío, río que la separa físicamente del fuerte de Nacimiento, limitando al norte con las tierras de los Valdebenitos y la hacienda Huaqui propiedad de la Compañía de Jesús, y al este, estero Coyanco por medio, con el llano de Negrete que forma parte de las tierras propias de la reducción. ${ }^{12} \mathrm{Al}$ mismo tiempo, el mapa señala la existencia de un fuerte al interior de su territorio, situado en el cerro Mesamávida.

En cuanto al modo de vida de sus habitantes, el informe asegura que es el mismo que se observa en San Cristóbal, es decir "los indios que la componen son de reducción, o sujetos a la dominación española y cristianos de origen, aunque no tienen pueblo formal, pues viven con alguna dispersión en chozas pajizas, que llaman ranchos o ramadas". ${ }^{13}$

A continuación se inserta una matrícula o padrón de sus habitantes (ver Tabla 1), afirmando, en primer lugar, que "en general componen esta reducción ochocientas cuatro personas, con la distinción de clases, estado, edad, y sexo que sigue": ${ }^{14}$

que como se ha visto existía como tal en 1618, si bien no resulta posible evidenciar una persistencia continua en el tiempo de una misma población asentada en ella.

12 Este factor explica la celebración de los parlamentos en los terrenos del llano de Negrete. Por otra parte, los Valdebenito y sus descendientes (particularmente los Rey y Jibaja) fueron capitanes de amigos de la reducción y lenguaraces del Real Ejército. Los jesuitas ejercieron de capellanes-misioneros en ella, antes de 1724 desde el colegio de Buena Esperanza de Rere, casa a la que pertenecía la hacienda San Joseph de Huaqui, y a partir de esta fecha con una casa misional en la misma reducción. Esta última innovación se debe, a todas luces, a la intención de la Compañía de no perder, al menos nominalmente, terreno en el número de misiones, debido al abandono de las casas misionales situadas en la tierra adentro, a raíz del levantamiento de 1723-1724.

13 Correspondencia del presidente Ambrosio Benavides, 1784-1785, AGI, Chile, vol. 193, sin foliar.

14 Correspondencia del presidente Benavides, 1784-85, AGI, Chile, vol. 193. Si bien la matrícula del Obispado de la Concepción confeccionada por el mismo obispo Marán en 1781 consigna para la reducción de Santa Fe 


\begin{tabular}{|l|l|c|}
\hline Clase, estado y sexo & Edad & Cantidad \\
\hline Hombres casados & de más de 40 años & 40 \\
\hline Ídem & de 20 a 40 años & 124 \\
\hline Viudos & de más de 20 años & 13 \\
\hline Solteros & de 8 a 20 años & 101 \\
\hline Párvulos & & 91 \\
\hline Mujeres casadas & de más de 40 años & 40 \\
\hline Ídem & de 20 a 40 años & 124 \\
\hline Viudas & de más de 20 años & 36 \\
\hline Solteras & de 8 a 20 años & 123 \\
\hline Párvulas & & 112 \\
\hline Total & & 804 \\
\hline
\end{tabular}

Tabla 1. Matrícula de Santa Fe, 1785.

Fuente: Correspondencia del presidente Ambrosio Benavides, 1784-1785, AGI, Chile, vol. 193, sin foliar.

Resulta ilustrativo comparar estos datos con los ofrecidos para San Cristóbal (ver Tabla 2). Dicha reducción, según expresa el mismo documento, está compuesta solamente por 180 personas, empadronadas de la siguiente manera:

\begin{tabular}{|l|l|c|}
\hline Clase, estado y sexo & Edad & Cantidad \\
\hline Hombres casados & de más de 40 años & 13 \\
\hline Ídem & de 20 a 40 años & 26 \\
\hline Viudos & de más de 20 años & 4 \\
\hline Solteros & de 8 a 20 años & 29 \\
\hline Párvulos & & 24 \\
\hline Mujeres casadas & de más de 40 años & 9 \\
\hline Ídem & de 20 a 40 años & 30 \\
\hline Viudas & de más de 20 años & 9 \\
\hline Solteras y párvulas & de 8 a 20 años & 36 \\
\hline Total & & 180 \\
\hline
\end{tabular}

Tabla 2. Matrícula de San Cristóbal, 1785.

Fuente: Correspondencia del presidente Ambrosio

Benavides, 1784-1785, AGI, Chile, vol. 193, sin foliar.

un total de 486 individuos entre adultos y párvulos. Cf. Correspondencia sobre fortificaciones, pertrechos y situados, 1780-1785, AGI, Chile, vol. 436, sin foliar.
Como se puede apreciar, la población de Santa Fe cuadruplica aquella de San Cristóbal. Este hecho es relevante y no puede ser fortuito. Relevante, porque San Cristóbal no solamente es una reducción mucho más antigua, según el mismo informe "se fundó el año de 1646 a cargo de los exjesuitas por el gobernador don Martín de Mujica", ${ }^{15}$ sino que también había representado una pieza mucho más importante en el engranaje colonial fronterizo, especialmente durante el siglo XVII. ${ }^{16}$

En cuanto a la asimilación cultural de los habitantes de Santa Fe, en particular al uso de la lengua española, al igual que en relación a San Cristóbal, se afirma que "entienden_generalmente la lengua española, pero entre sí no la usan, sino la propia y antigua de sus naciones, que es común y no diferente en todas las de indios de este dominio, así reducido, como infieles". ${ }^{17}$ Este acápite encierra un elemento muy importante, que comprende y explica la función de Santa Fe, junto con las otras reducciones fronterizas, de servir como mediadora al mundo de la tierra adentro, papel en el cual la afinidad lingüística es de fundamental importancia. En efecto, este rol se ve simbólicamente representado en la vocería que ejerce, tradicionalmente, el cacique santafecino a lo largo del ciclo de parlamentos fronterizos del siglo XVIII. ${ }^{18}$

15 Correspondencia sobre fortificaciones, pertrechos y situados, 1780-1785, AGI, Chile, vol. 436, sin foliar.

16 La reducción de San Cristóbal figura asiduamente en la documentación del siglo XVII, perdiendo ostensiblemente protagonismo en el XVIII en favor de Santa Fe. Esta mutación en la importancia fronteriza parece fundamentarse principalmente en la geográfica de ambas reducciones (Santa Fe se encuentra más próxima a la ribera del Biobío), así como en la importancia estratégica del fuerte que las acompaña (Nacimiento adquiere preponderancia durante este período en comparación con Yumbel). Cf. Información de Diego de Vivancos, 1650, AGI, Chile, vol. 46, sin foliar; Cartas de la Audiencia, 26-IX-1660, AGI, Chile, vol. 13, sin foliar; Cartas de la Audiencia, 20III-1663, AGI, Chile, vol. 13, sin foliar; Cartas de Gobernadores: José de Garro, 4-I-1684, AGI, Chile, vol. 24, sin foliar; Cartas de Gobernadores: Tomás Marín de Poveda, 26-IV-1693, AGI, Chile, vol. 25, sin foliar.

17 Correspondencia del presidente Ambrosio Benavides, 1784-1785, AGI, Chile, vol. 193, sin foliar.

18 Así por ejemplo se expresa en los informes del Parlamento de Lonquilmo (1783): “... concluida esta diligencia pidió licencia el cacique gobernador de la reducción de Santa 
A partir del punto sexto, el cuestionario se refiere a la "asistencia espiritual". En éste se informa que "desde el extrańamiento de los exjesuitas se puso esta misión a cargo del ordinario de aquel obispado, quien la provee de un eclesiástico secular por su nombramiento y elección, sin conocimiento del real patronato". ${ }^{19}$ En el mismo contexto, en el punto séptimo, se especifica la capacidad del cura doctrinero de expresarse en la lengua materna de sus feligreses. En relación al cura de San Cristóbal, se había afirmado que "del actual no se duda del desempeño de su ministerio en aquellos cargos conducentes a la cura de almas: posee el idioma de sus feligreses, aunque al tiempo de su provisión, como ni los demás de su clase, no fue examinado de su inteligencia en él”. ${ }^{20}$ En cuanto al doctrinero de Santa Fe, el redactor del informe se ve obligado a precisar: "lo mismo que el de la precedente, excepto en la inteligencia del misionero en el idioma de estos naturales, que se suple por la que ellos tienen del español, concurriendo también la particular circunstancia de haber solicitado esta misión por su cacique, que en lugar del sacerdote secular que la gobierna, se le subroguen de los regulares del colegio de Chillán; pero como el ordinario de la Concepción, a cuyo cargo se halla, lo ha resistido ha sido conveniente por ahora, no innovar este establecimiento". ${ }^{21} \mathrm{Al}$ parecer los miembros

Fe a quien le incumbe hablar por el Butalmapu de la cordillera que corresponde al sargento mayor...”. Provisiones de empleos políticos y militares, 1785-1825, AGI, Chile, vol. 184, sin foliar. Lo mismo en el Parlamento de Negrete (1793): "En cuyo estado pidió permiso para hablar el cacique cristiano de la reducción de Santa Fe don Juan de Lebuepillán por virtud de la antigua prerrogativa que sobre esto le compete...". Correspondencia del presidente Ambrosio O'Higgins, 1793-1794, AGI, Chile, vol. 199, 55 v. En realidad esta "prerrogativa” no parece ser más antigua que el Parlamento de Negrete (1771), en el cual los caciques del Butalmapu de la cordillera eligen a Ignacio Levihueque para que hable a su nombre en virtud del rol mediador desarrollado por éste en las paces que pusieron fin al alzamiento que tuvo lugar en aquel tiempo. Se advierte por lo tanto la intensión de la administración colonial de fomentar costumbres a su favor como si estás fueran de larga data.

19 Correspondencia del presidente Ambrosio Benavides, 1784-1785, AGI, Chile, vol. 193, sin foliar.

20 Correspondencia del presidente Benavides, 1784-85, AGI, Chile, vol. 193.

21 Correspondencia del presidente Benavides, 1784-85, AGI, Chile, vol. 193. Esta situación se perpetuaba aún en el Parlamento de Negrete (1803): "La reducción de de la reducción no se encuentran muy conformes con el cura secular que los asiste. Como lo señala el mismo documento, éste no se desenvuelve en la lengua de la tierra, lo cual obliga a los habitantes de la reducción a emplear el español en las cosas de la Iglesia (particularmente la confesión). Esta situación, quizás unida a otras, parece generar un conflicto que motiva al cacique a solicitar el reemplazo del actual clérigo por un misionero franciscano de Chillán. Petición que es "resistida" por Francisco José Marán, obispo de Concepción. Este conflicto al interior de la reducción debió ser bastante álgido porque se han conservado trazas de él en las actas de los parlamentos de la época y otros repertorios. ${ }^{22}$

\section{Tipo de organización familiar}

La historia de los hermanos Lorenzo Queupuante y Francisco Leviguir puede contribuir a comprender las dinámicas de organización familiar en la reducción de Santa Fe en una etapa temprana de su refundación a principios del siglo XVIII. La información existente en cuanto a sus personas y sus familias resulta característica de la situación de frontera, al mismo tiempo que permiten una mirada en la vida familiar y los patrones de asentamiento en una reducción fronteriza.

Según los documentos conservados en el fondo Jesuitas del Archivo Nacional chileno, ambos hermanos residían en Santa Fe en el año de 1709. En aquel tiempo, Diego Roco, rector del colegio de la Compañía de Jesús en Rere, emprendía gestiones ante el

Santa Fe, compuesta de su gobernador y caciques, con los de Angol, Maquegua, Lebcoyan, y generalmente los más de la tierra, suplicaron la solicitud de su difunto gobernador Levihueque, que hizo en el parlamento general el ańo pasado de mil setecientos noventa y tres para que se les diese misioneros de propaganda en lugar del cura que les tienen puesto...”. Correspondencia del presidente Luis Muñoz de Guzmán, 1803, AGI, Chile, vol. 204, sin foliar.

22 Correspondencia del presidente Benavides, 1784-85, AGI, Chile, vol. 193. Informes sobre la reducción de Santa Fe a instancias de la petición del cacique Ignacio Levihueque, 1789, AOSF, Chillán, Asuntos Varios (1787-1790), vol. 6, pieza 57, 144-159v; Expediente formado a instancia de Ignacio Levigüeque, cacique gobernador de la reducción de Santa Fe relativo a que le provea a su reducción de padres misioneros en lugar de su actual párroco, 1788, ANH, Fernández Larraín, vol. 71, pieza 1, 1-38v. Esta última pieza ha desaparecido actualmente del volumen. 
corregidor del partido para obtener su extracción de la reducción y su asentamiento como "indios de servicio" en la hacienda Ventura, propiedad de aquel colegio. Este proceso pone de manifiesto, en alguna medida, el factor jugado por la reducción como un ámbito de excepción y en este sentido de protección.

A fin de comprender la situación jurídica de ambos hermanos y las pretensiones del rector jesuita, se ha de tener presente que Lorenzo y Francisco fueron hijos de Juan Colerum, un "indio libre" de la tierra adentro que durante la segunda mitad del siglo XVII llegó, como tantos otros y luego de un complejo proceso, a asentarse, "reducirse" dirían los textos oficiales, a Santa Fe. Las motivaciones que pudo tener son un misterio. A partir de la documentación producida en torno a este caso, entre los años $1694 \mathrm{y}$ 1710 , es posible reconstruir una biografía plausible de él y su familia (ver Tabla 3).

\begin{tabular}{|l|l|}
\hline & Es padre de un hijo, llamado Juan, en la "tierra adentro" \\
\hline $\mathbf{1 6 7 4}$ & Comienza a servir al colegio de Buena Esperanza \\
\hline & Contrae primer matrimonio según rito de la Santa Iglesia \\
\hline & Contrae segundo matrimonio según rito de la Santa Iglesia con Juana india \\
\hline $\mathbf{1 6 9 4}$ & Su hijo, Lorenzo Quetepuan, contrae matrimonio según rito de la Santa Iglesia \\
\hline $\mathbf{1 6 9 5}$ & Gestiones de los jesuitas para que retorne al servicio en la hacienda \\
\hline $\mathbf{1 6 9 6}$ & Alega ser cacique \\
\hline $\mathbf{1 7 0 7}$ & Es ya difunto \\
\hline $\mathbf{1 7 0 9}$ & Comparece su hijo Lorenzo Quetepuan \\
\hline $\mathbf{1 7 1 0}$ & Autos contra sus hijos Lorenzo Quetepuan y Francisco Leviguir \\
\hline & Comparece otra vez su hijo Lorenzo Quetepuan, residente en Santa Fe \\
\hline & Lorenzo Quetepuan deja en prenda a su hermana Juana y a su hijo Lorenzo \\
\hline
\end{tabular}

Tabla 3. Biografía de Juan Colerum.

Fuente: Indios que fueron del sargento mayor Francisco Rodríguez, 1692, ANH, Jesuitas, vol. 73, pieza 18, 38-39v; Causa contra Juan Colerum, 1696, ANH, Jesuitas, vol. 73, pieza 25, 51-52v; Memorial de amparo sobre indios donados por Francisco Rodríguez, 1692-1695, ANH, Jesuitas, vol. 73, pieza 109: 220-223v; Autos contra los dos hijos de Juan Colerum, 1709, ANH, Jesuitas, vol. 73, pieza 117, 238-240v; Pleito contra Juan Colerum, indio asentado en Santa Fe, 1694, ANH, Jesuitas, vol. 94, 73-74; Retorno de la familia de Juan Colerum a la estancia de la compañía, 1707, ANH, Jesuitas, vol. 94, 90-90v;

Deuda de Lorenzo Qeupuante hijo de Juan Colerum indio de Santa Fe, 1710, ANH, Jesuitas, vol. 94, 97.

El indio Juan Colerum había nacido en la tierra adentro, a pesar de que un documento afirma que era natural de Santa Fe. ${ }^{23}$ El lugar exacto de su nacimiento tampoco resulta claro, porque el mismo Juan alega ser hijo de los caciques de la reducción de Curi, en cambio un testigo lo sindica como "un indio pobre y desvalido de los que llaman mitayos", nacido en la reducción de "Mollchen". ${ }^{24}$ Con pos-

23 Sebastián de la Barra, rector jesuita, contra Juan Colerum, 1695, ANH, Jesuitas, vol. 73, pieza 51, 112-113.

24 Autos contra los dos hijos de Juan Colerum, 1709, ANH, Jesuitas, vol. 73, pieza 117, 239-239v. terioridad al alzamiento de 1655, pero antes del año 1674 , emigra de la tierra adentro, junto a un hijo llamado Juan y un sobrino llamado Bernardo, para asentarse como indio libre al servicio de los jesuitas en Buena Esperanza de Rere. El caso es que Colerum no solamente se emplea al servicio de los jesuitas, sino que al mismo tiempo contrae matrimonio canónico con una india depositada en dicho colegio pagando el precio a la usanza, cuyo monto fue cancelado a modo de préstamo por los padres jesuitas. ${ }^{25} \mathrm{Al}$ enviudar de su primera mujer legíti-

25 Pleito contra Juan Colerum, indio asentado en Santa 
ma, contrae segundas nupcias empleando el mismo sistema, con una india llamada Juana, quien era natural de la hacienda Ventura. Esta segunda mujer de Juan Colerum habría sido hija de un indio esclavo, cogido "en guerra viva" en tiempos del gobernador Mujica y donado al colegio por su antiguo amo. Ella parece ser la madre de los tres hijos de Juan, dos varones y una mujer, mencionados en los autos. El mayor de ellos es Lorenzo, quien contrae matrimonio, una vez más según el doble sistema usanza-canónico, con una india residente en Santa Fe. ${ }^{26}$

Hacia el año 1694 Juan Colerum se encuentra, junto a su mujer y su hija, empleado en calidad de vaquero en la hacienda San Joseph de Huaqui, única propiedad de la Compañía en la Isla de la Laja. A raíz de un confuso hecho que involucra a su hijo Lorenzo, decide abandonar el servicio y trasladarse a la reducción de Santa Fe, contigua a la hacienda. En aquel preciso instante los jesuitas inician gestiones para obtener su retorno, el que nunca se concreta.

En cuanto al estatuto de sus hijos. Su hijo Francisco Leviguir habría confesado "haberse criado en dicho colegio, sirviendo a los padres misioneros, después que la dicha Juana su madre, cautiva de los bárbaros en el alzamiento, fue rescatada por los padres de dicho colegio; de donde se pasó a servir al licenciado don Juan de Rebollar, quien a la hora de la muerte le mandó se volviese al servicio de dichos padres con cuyo permiso la había tenido en su poder...". ${ }^{27}$ Este fragmento del testimonio de Francisco no solamente proporciona datos sobre la situación legal de un hijo de madre depositada, sino que a la vez describe la compleja situación que afecta a los individuos indígenas durante este período, caracterizada por su obligación al servicio y por los efectos del alzamiento general de mediados de siglo.

Por otra parte, por aquella fecha, según argumenta el jesuita Diego Roco, la mujer e hijos de Francisco Leviguir se encuentran en la hacienda de Picul, " $y$ su hermana nombrada Juana en poder del teniente

Fe, 1694, ANH, Jesuitas, vol. 94, 73-74.

26 Memorial de amparo sobre indios donados por Francisco Rodríguez, 1692-1695, ANH, Jesuitas, vol. 73, pieza $109,222 \mathrm{v}-223$.

27 Autos contra los dos hijos de Juan Colerum, 1709, ANH, Jesuitas, vol. 73, pieza 117, 239.
Juan Antonio mílite del fuerte del Nacimiento vendida por dicho su hermano Lorenzo Queupuante" ${ }^{28}$ Este último representa un dato no menor, que parece tener su explicación en una importante dicotomía del sistema hispano colonial: por una parte, la recurrente denuncia ventas ilegales llevadas a cabo incluso entre los indios reducidos, y por otra las exigencias planteadas por los mismos jesuitas en función de que Lorenzo pague la deuda que ha contraído su familia.

Por lo tanto, como se puede observar la biografía de Juan Colerum y sus parientes se caracteriza por una importante fluidez en cuanto a su vida familiar y sus lugares de asentamiento. La articulación de su núcleo familiar puede ser representada según el diagrama siguiente (Figura 2):

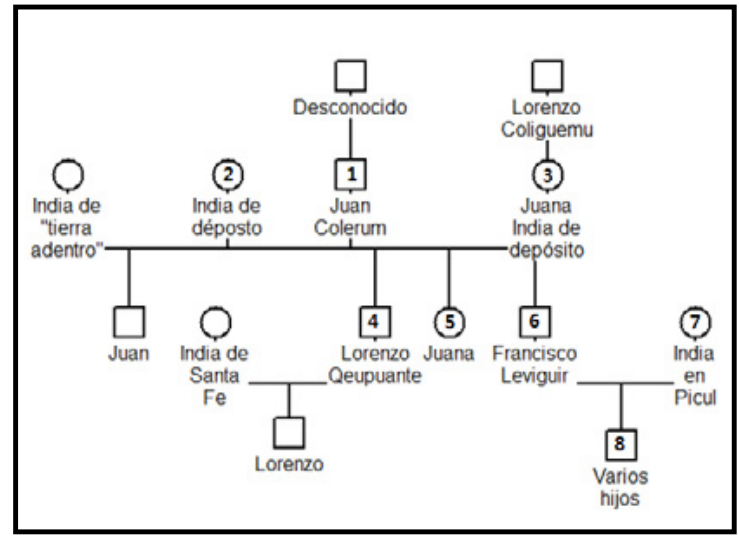

Figura 2. Familia de Juan Colerum.

Fuente: Indios que fueron del sargento mayor Francisco Rodríguez, 1692, ANH, Jesuitas, vol. 73, pieza 18, 38-39v; Causa contra Juan Colerum, 1696, ANH, Jesuitas, vol. 73, pieza 25, 51-52v; Memorial de amparo sobre indios donados por Francisco Rodríguez, 1692-1695, ANH, Jesuitas, vol. 73, pieza 109, 220-223v; Autos contra los dos hijos de Juan Colerum, 1709, ANH, Jesuitas, vol. 73, pieza 117, 238-240v; Pleito contra Juan Colerum, indio asentado en Santa Fe, 1694, ANH, Jesuitas, vol. 94, 73-74; Retorno de la familia de Juan Colerum a la estancia de la compañía, 1707, ANH, Jesuitas, vol. 94, 90-90v; Deuda de Lorenzo Qeupuante hijo de Juan Colerum indio de Santa Fe, 1710, ANH, Jesuitas, vol. 94, 97.

28 Autos contra los dos hijos de Juan Colerum, 1709, ANH, Jesuitas, vol. 73, pieza 117, 239. 
A fin de cuentas, todos los datos disponibles parecen configurar un escenario extremadamente complejo. Juan Colerum (1), natural de la tierra adentro, emigra a tierra de espańoles. Contrae dos veces matrimonio (2-3) según una dinámica hibrida, que incluye tanto las pagas a la usanza como el rito eclesiástico hispano. Con su segunda pareja procrea al menos tres hijos (4-5-6). Todos parecen residir a lo largo del tiempo en ámbitos diversos: la madre es india de servicio en Nacimiento (3); la hermana es "vendida” a un mílite del mismo presidio (5); ambos hermanos residen en Santa Fe (4-6), pero la mujer de uno de ellos (7), junto a sus hijos (8), se encuentra en la hacienda de Picul. Estos patrones de asentamiento fluido incluyen la abducción de la madre (3) en tiempos del alzamiento general y su traslado a la tierra adentro, un fenómeno característico de este período.

\section{El estigma "aillacuriche"}

El padre Ignacio Guzmán, rector del colegio de San Francisco Javier de la villa de Buena Esperanza, se presentaba ante el corregidor del partido, Joseph Díaz, el 4 de mayo de 1765, unos dos ańos antes de la expulsión de los regulares de la Compañía de Jesús. El objeto de su comparecencia era obtener, de parte de la autoridad, un mandato que obligase a un considerable conjunto de personas indígenas a reducirse al servicio del mencionado colegio jesuita. ${ }^{29}$ Gracias a la documentación generada en este proceso, es factible conocer las actividades, lugares de residencia, parentesco y origen de este grupo familiar vinculado a la reducción de Santa Fe, pero también a la zona de Quilale, a la estancia de los Coloma, o incluso "arranchados en la Cordillera".

Esta documentación reviste especial interés en el contexto de este artículo, en particular porque no solamente evidencia la génesis histórica que llevó a un grupo familiar específico a asentarse en Santa Fe, sino que al mismo tiempo describe el contexto en el cual se encuentra inserta la reducción. En efecto, como se aprecia a continuación, Santa Fe no representa ni de lejos el único lugar donde los hijos de la tierra se

29 Ignacio Guzmán de la Compañía de Jesús ante Joseph Díaz, corregidor y justicia mayor del partido de Rere, 1765, ANH, Jesuitas, vol. 94, 69-70v. instituyen como ocupantes del territorio. Las formas según las cuales los individuos indígenas llegan a ser "dueños de la frontera" en tierras de españoles son múltiples y obedecen a patrones diversos. Entre ellas se encuentran por supuesto el reducirse en el espacio destinado para ellos por la autoridad colonial, pero también el arrancharse en la cordillera, presumiblemente en tierras vacas, o el afincarse como peones o inquilinos en alguna estancia fronteriza con derecho a trabajar algún retazo de terreno.

Según el testimonio presentado por el rector, redactado con el fin de avalar el derecho que asiste al colegio en esta pretensión, este grupo humano estaría compuesto por descendientes de "aillacuriches", lo cual justificaría su condición de "indios de servicio". En efecto, según Guzmán, los antepasados de todos ellos serían dos individuos: el uno llamado Francisco Tenaqueu, y el otro, Domingo Liempí, quienes habrían pertenecido a dicha parcialidad.

Si se confronta la argumentación desarrollada por el cura rector con documentación más antigua, conservada asimismo en el fondo Jesuitas, la denominación "aillacuriche", en ambos casos resulta ser completamente falsa, y por lo tanto parte de una clásica estrategia colonial, extremadamente vigente en la frontera indígena chilena: se trata de la función que se confiere al denominar a una persona como una forma de "etiquetarla" en una cierta categoría. Estas categorías, a su vez, justifican derechos, obligaciones, roles y pretensiones.

¿Qué implica la etiqueta de "aillacuriche"? A partir del gobierno de Juan Henríquez (1670-1682) se denominó de esta manera a los miembros de la parcialidad de Viluco liderada por el cacique de este nombre. Este grupo, extremadamente activo en contra de la ocupación hispana, será el blanco no solamente de una dura represión, sino que a la vez el objeto de una importante codicia esclavista. A partir de este contexto, "aillacuriche" adquiere un significado afín a otras etiquetas vigentes durante este período, tales como: "aucas", "rebeldes", "indios de guerra", "bárbaros" e "infieles", entre otras (Obregón Iturra, 2010). Esta identificación, que funcionará en la ya tradicional acepción de rebelde = esclavo, se verá confirmada por las masivas deportaciones de los aillacuriches y por su venta como esclavos, 
en particular a propietarios de la zona fronteriza (Chuecas, 2017). Como se observa, en la construcción de este "imaginario sobre el servicio" están funcionando categorías de larga data en la historia de Occidente, en particular elementos procedentes de la cultura helenista, en cuyo contexto los pensadores clásicos “inventaron" la noción según la cual el mundo se divide entre ciudadanos y bárbaros, señores y esclavos.

Ahora bien, cuando Ignacio Guzmán emplea el término, no ofrece una explicación explícita en cuanto a lo que significa pertenecer a la categoría "aillacuriche". Según su argumento, un descendiente de aillacuriche ha de ser considerado evidentemente como un "indio de servicio". He aquí un juego de ambigüedad. En realidad, a estas alturas, en la segunda mitad del siglo XVIII, aillacuriche ya no es justificación para ningún tipo de coerción al trabajo indígena. La cédula que pone fin a la esclavitud había instituido el llamado "depósito", a su vez una etiqueta ambigua, que debía regir por un tiempo hasta otorgar la libertad ( $\mathrm{Ha}-$ nisch, 1981; Hanisch, 1991). En ningún momento se menciona en la documentación oficial la calidad heredable del depósito o del "aillacurichismo". Ciertamente que lo que aquí sucede es una forma de asimilación oportunista al sistema de encomienda. En resumen, en la segunda mitad del XVIII se continúa con una situación extremadamente confusa y servicial a los intereses coloniales.

Por otra parte, la comparación con fuentes anteriores evidencia que tanto Francisco Tenaqueu como Domingo Liempí no tienen, de hecho, nada de "aillacuriches". Unos 72 años antes de este evento, el 22 de diciembre de 1692, uno de los antecesores de Ignacio Guzmán, el padre rector Marcos del Castillo, también gestionaba el derecho a la propiedad sobre el trabajo de un grupo de indígenas, entre los que se encontraban justamente los mencionados Francisco y Domingo. ${ }^{30}$ Según el relato desarrollado en el escrito de Castillo, ambos indios, junto con otros tres, habrían formado parte de los bienes que el sargento mayor Francisco Rodríguez donó al colegio hacia 1662 ("hace más de 30 años"). Dichos bienes consistirían en una estancia y todos los indios esclavos que poseía, "de los cuales algunos de ellos se

30 Indios que fueron del sargento mayor Francisco Rodríguez, 1692, ANH, Jesuitas, vol. 73, pieza 18, 38-39v. fueron a la tierra dentro en tiempo del alzamiento general y después de pasado éste fueron volviendo de su voluntad a dicha estancia". ${ }^{31}$ En este contexto Castillo afirma que Francisco "Tanaqueo" es padre de "cuatro hijos nombrados Ignacio, Lorenzo, Juan y Pedro", y Domingo "Llienpil" de "dos hijos Joseph y Domingo". Al mismo tiempo menciona a Juan Luis, hermano de Domingo Liempí. Como se puede apreciar, estos esclavos formaban previamente redes familiares.

Por otra parte, en el marco de su argumentación en 1765, Ignacio Guzmán describe la presunta genealogía de los implicados y los lugares donde se encuentran residiendo los descendientes de Tenaqueu y Liempí (ver Figura 3).

Según este relato, una parte de ellos descendería de Francisco Tanaqueu (1), originario de la "reducción nombrada Aillacuriche", residentes en aquel momento en la estancia Ventura, propiedad de la Compañía. Se trata de Gabriel (2), alías "el capataz", y sus hijos Juana (3), Juan (4), Ignacio (5), que llaman "el Flaco", Sebastián (6), y otra hermana (7) que casó en la estancia de los señores Colomas, cita en la Isla de la Laja, "y los descendientes de todos éstos que son muchos". También desciende de Francisco Tanaqueu el indio Juan de Dios (8), casado "con Josepha (9) india que servía en la cocina de dicho colegio", quien también era india de depósito, cuyos hijos son Javier (10), Francisco (11), Simón (12), Lorenzo (13), Bernarda (14) y Gregoria (15). Otros descendientes de Tanaqueu serían Bartolo (16) y Juana (17), madre de Prudencio Contreras (18) y de Juan Rivas (19). Así como también Lorenzo (20), cuyas hijas son María (21) y Pascuala (22) "que están huidas en la Concepción".

Al grupo de los supuestos aillacuriches pertenecerían también los descendientes de Domingo Liempí, quien habría tenido varios hijos, "y de uno de ellos descendió el indio Tuy, que casó con Teresa india, también de dicha parcialidad". De éstos descienden María, mujer de Joseph, que llaman "el Coco"; Flora, mujer de Prudencio Contreras; Ignacia, mujer de Esteban, y Petrona, mujer de Bernardo, "de las que

31 Indios que fueron del sargento mayor Francisco Rodríguez, 1692, ANH, Jesuitas, vol. 73, pieza 18, 38-39v. 


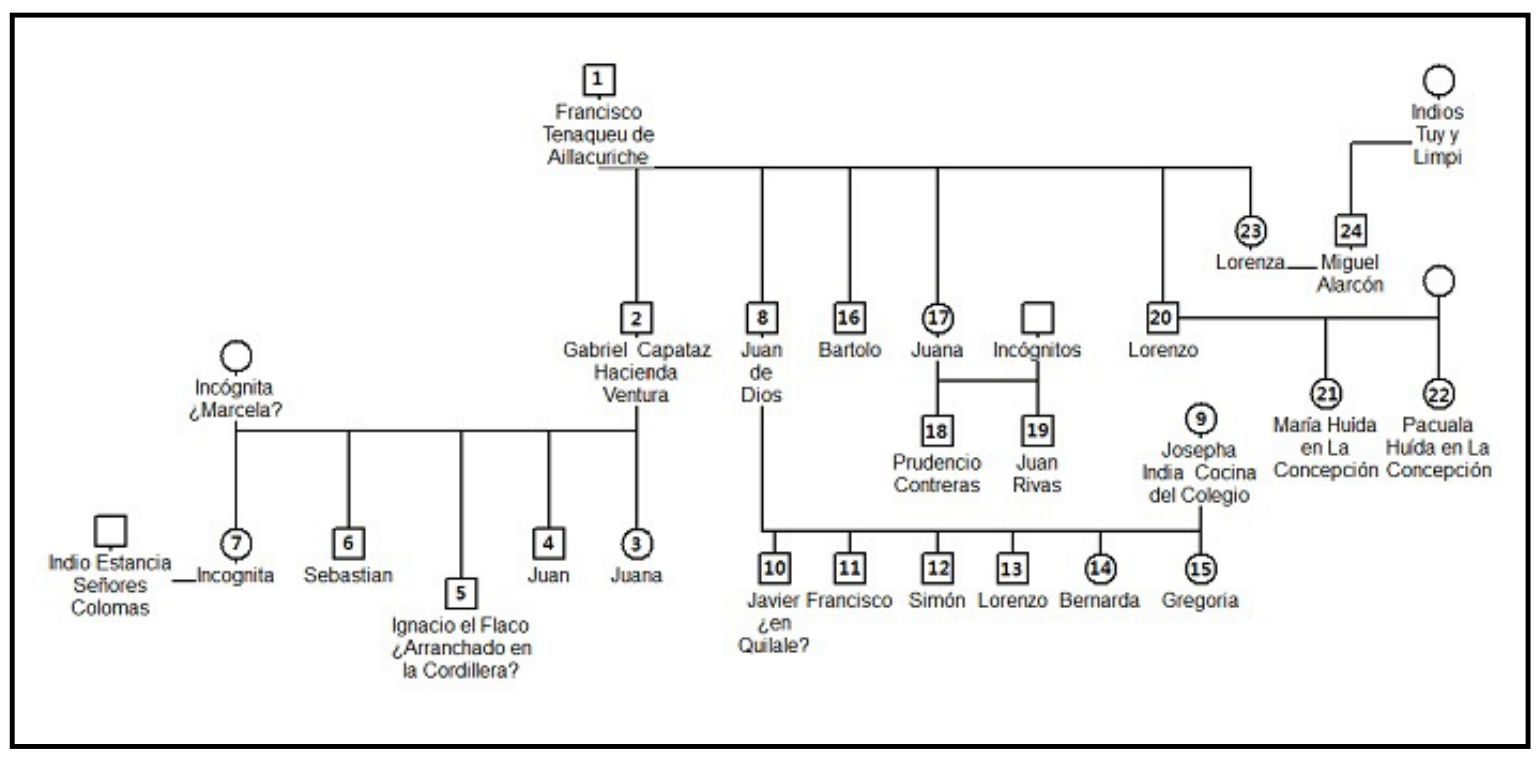

Figura 3. Descendencia de Francisco Tanaqueu y Domingo Liempí.

Fuente: Ignacio Guzmán de la Compañía de Jesús ante Joseph Díaz corregidor y justicia mayor del partido de Rere, 1765, ANH, Jesuitas, vol. 94, 69-70v.

hay varios descendientes así hombres como mujeres". A este grupo de parentesco pertenece también "la india llamada Flora que casó con el indio Lorenzo", cuya hija Juana casó "con el indio Marilab de la tierra dentro", cuyos hijos serían Miguel, Bartolo, Marcos, Juana de la Cruz, María Rosa y Mariana, "los que tienen varios descendientes, así hijos como hijas, que se hallan hoy en servicio del colegio". ${ }^{32}$

Por último existen individuos que descenderían de ambas líneas. Se trataría en este caso de Lorenza (23), descendiente de Francisco Tanaqueu, mujer que fue de Miguel Alarcón (24), "de la que quedaron varios hijos e hijas", constando según Ignacio Guzmán, "que dicho Miguel Alarcón desciende por parte de madre de los indios Tuy y Liempí".

$\mathrm{Al}$ mismo tiempo existe un grupo de ocho varones que "no son oriundos de dichos indios depositados; más por haber contraído matrimonio con las indias descendientes de los dichos quedaron también bajo de dicho amparo y deposito en dicho colegio". Al interior de este subgrupo,

[...] consta ser descendientes de dichos indios depositados la india Josepha que llaman

32 Indios que fueron del sargento mayor Francisco Rodríguez, 1692, ANH, Jesuitas, vol. 73, pieza 18, 38-39v.
Rocha y los hijos de ésta por consiguiente que se llaman Guińemilla casado en la misión de Santa Fe, la india Cecilia, Ignacia y Antonia, y los descendientes de éste y de éstas, como así mismo la india Bernarda casada con Miguel Marilab. ${ }^{33}$

Al concluir estos autos Joseph Díaz, corregidor del partido de Buena Esperanza de Rere, decretaba que,

[...] por tanto juzgué que debía mandar y mandé que los indios que de esta parcialidad han hecho fuga del real deposito sean [a él] restituidos; y respecto de que el indio Ignacio hijo de la [Marcela] está arranchado en la cordillera, el indio Quinemilla en la misión de Santa Fe, y el indio Javier en el paraje nombrado Quelale, se les notifique este mi decreto por cualquier persona que sepa leer y escribir para que en término de [tres] meses, que se contaran desde el día de la notificación so pena de cincuenta azotes en el rollo de esta villa y de ir desterrado por

33 Ignacio Guzmán de la Compañía de Jesús ante Joseph Díaz corregidor y justicia mayor del partido de Rere, 1765, ANH, Jesuitas, vol. 94, 69-70v. 
un año a rasión y sin sueldo a la plaza de el Nacimiento se transporten con sus familias a la estancia de dicho colegio de la compañía de Jesús nombrada Ventura.... ${ }^{34}$

\section{Jerarquía en el gobierno de la reducción}

Figura clave en el sistema reduccional es sin duda el cacique (gülmen). En el caso de Santa Fe no resulta factible hablar de este rol de autoridad sin hacer referencia a Ignacio Levihueque, máximo representante de esta función durante toda la existencia de la reducción. Antes de analizar los datos disponibles sobre su persona, es preciso realizar algunas observaciones previas. En general no existen repertorios importantes que refieran a Santa Fe, las tierras de la reducción, o la figura de su cacique gobernador. En segundo lugar, se ha de tener presente que Levihueque representa un ejemplo relevante de lo que se debe designar como "cacicazgo colonial". ${ }^{35} \mathrm{Su}$ situación como cabeza principal de los indios reducidos de Santa Fe no es equiparable, sin más, con la función similar ejercida por los gülmen de "tierra adentro" durante este período, ni mucho menos con los sistemas de autoridad indígena en otros contextos americanos (Hidalgo, 2004; Hidalgo y Castro, 2004). Se trata de un tipo de cacicazgo inserto y desarrollado a partir del sistema de reducción fronteriza chilena. Por otra parte, se ha de considerar que el largo período en que Levihueque se encuentra a la cabeza de la reducción coincide con el período de auge de Santa Fe. ${ }^{36}$

Sobre los inicios de su gestión es poco lo que se sabe, situación análoga a la de otros señores de la tierra adentro. Sus orígenes son difusos, siendo factible tan solo suponer el papel que han jugado, en su acceso a esta categoría de poder, el linaje y la

34 Ignacio Guzmán de la Compañía de Jesús ante Joseph Díaz corregidor y justicia mayor del partido de Rere, 1765, ANH, Jesuitas, vol. 94, 69-70v.

35 Para el caso chileno existen muy pocos trabajos sobre caciques coloniales. Cf. Guarda, 1968. Para otros ámbitos de la América hispana, cf. Gibson, 1984; Jurado, 2014.

36 Este factor se ve retratado en la relevante participación de este cacique en los parlamentos generales del siglo XVIII. Cf. Zavala, 2015, 288, 294, 300, 301, 307, 308, $316,324,353,363$ у 390 . adquisición de patrimonio y autoridad moral. A grandes rasgos son estos tres elementos los que usualmente acompañan a los gülmen. Ellos han de pertenecer a los linajes de grandes señores, descender por ambas líneas de las familias poderosas, estar bien emparentados y controlar un patrimonio importante que les permita agasajar y mantener al conjunto de individuos que se acogen a su protección. En el caso de un organismo social, como es una reducción fronteriza, sus antecedentes familiares han de estar ligados a los orígenes de la reducción. ${ }^{37}$ En otras palabras, no se puede tratar de un indio allegado, ni mucho menos del común.

En cuanto a sus padres, no se sabe prácticamente nada, resultando posible asumir, sin mayores evidencias, que debió haber sido hijo de su antecesor en el cargo. Esta hipótesis no resulta de fácil verificación. Sobre sus antecesores se sabe que en 1738 , al tiempo del Parlamento de Tapihue, era cacique gobernador de Santa Fe Ignacio Paillaguala, ${ }^{38}$ quien no necesariamente ha de ser su padre, pues podría tratarse de un hermano o tener otro tipo de parentesco. En este sentido, no ayudan los modos de apellidación, si bien Ignacio Levihueque tendrá, con toda seguridad, un hijo llamado Julián Leviluán ("guanaco veloz"), apellido que representa una variante del nombre de su padre.

El apelativo Levihueque puede ser traducido como "llamo veloz". En este caso el sustantivo hueque haría referencia a la llama (Lama glama) u "oveja de la tierra”. El chilihueque representaba un animal importante en el ceremonial tradicional y en las tratativas matrimoniales. Era un elemento representativo de estatus y riqueza, hasta que su función fue desplazada paulatinamente por animales domésticos introducidos. Sin duda, el nombre Levihueque es expresión de prestigio, sin que parezca tener

37 En un informe sobre el estado del Reino a la llegada del gobernador Garro, fechado en 1684, se habla de haber reducido a Santa $\mathrm{Fe}$ a un cacique no identificado expresamente, su familia y sus indios. Cf. Cartas de Gobernadores: José de Garro, 7-I-1684, AGI, Chile, vol. 24, sin foliar. Este hecho, ocurrido con posterioridad al alzamiento de 1655 , muy bien podría representar la recomposición de la reducción en la manera que perduraría durante el siglo XVIII.

38 Expediente de la fundación en Chile de dos poblaciones, 1748-1756, AGI, Chile, vol. 138, 13v-14. 
connotaciones guerreras como los nombres que incluyen términos como naguel (tigre/jaguar) u otros similares. Por otra parte, el cacique recibió un nombre cristiano al momento del bautismo: Ignacio. Se trata del apelativo del fundador de la Compañía de Jesús. El empleo de ambos apelativos parece ser reflejo de los mecanismos de asimilación vigentes en la frontera y en particular en las reducciones cristianizadas. Este último elemento es preponderante, porque la documentación disponible en relación a Santa Fe suele hacer referencia a la práctica de costumbres cristianas en el marco de la reducción como una característica esencial de su identidad.

El cargo de cacique gobernador (apo gülmen) es de creación colonial y está al servicio, al menos desde una perspectiva hispana, del proyecto colonial. ${ }^{39}$ $\mathrm{Su}$ función se expresa fundamentalmente en relación a sus pares y ha de ser confrontada a una noción más colegiada de la autoridad. En efecto, usualmente los caciques gobernadores suelen ser presentados al interior de un conjunto de caciques en las diversas parcialidades. ${ }^{40}$ En este contexto, resulta a lo menos sospechosa la singularidad de esta función. Es evidente el interés de la administración colonial de destacar a un individuo sobre otros con el fin de concentrar autoridad y posibilitar el dominio y el control.

En el caso de Ignacio Levihueque resulta indiscutible el hecho de su largo período de permanencia en el cargo. Levihueque figura como cacique gobernador en la documentación disponible, al menos entre los años 1759 y $1793 . .^{41} \mathrm{Al}$ parecer estuvo en funciones durante prácticamente toda la segunda mitad del siglo XVIII. Este largo período se caracterizó

39 Fenómenos similares bajo la rúbrica de "caciques gobernadores" se encuentran presentes en otros ámbitos americanos como es el caso de la Nueva España virreinal. Cf. Gibson 1984, 168-195.

40 Ésta es precisamente la situación en que suele figurar Ignacio Levihueque como primus inter pares a la cabeza de la reducción de Santa Fe. Cf. Causa criminal contra Juan Lebuepillán por homicidio en la persona de otro indio, 1766, ANH, CG, vol. 295, pieza 12, 344-356.

41 Salvador Cabrito contra Manuel de Amat, presidente y capitán general de Chile, sobre irregularidades en la pesquisa que se le formó, 1761, AHNM, Consejo de Indias, vol. 20419, exp. 3, 16-16v; Zavala, 2015, 288, 294, 300, 301, 307, 308, 316, 324, 353, 363 у 390. por momentos de crisis y otros de estabilidad. Estos factores significaron un desafío para la capacidad de negociación de los actores y por otra parte una amenaza y, a la vez, una oportunidad para la existencia de Santa Fe, dependiendo de la forma en que la reducción jugara sus cartas. En teoría recaía en la reducción el primado del butalmapu de los llanistas arribanos. ${ }^{42}$ Se trata, sin duda, de otra ficción de la administración colonial. De hecho en algunos documentos, Santa Fe figura a la cabeza del butalmapu de la cordillera y de los pehuenche. ${ }^{43}$ Esta función, a todas luces una creación hispana, se encuentra ligada a la preponderancia paulatina que adquirirán los parlamentos a lo largo del siglo XVIII como principal mecanismo de consolidación del statu quo fronterizo. En este sentido, el papel del cacique gobernador de Santa Fe en los parlamentos parece expresión de la naturaleza híbrida de la reducción al servicio de la situación ambigua imperante en la frontera. Ignacio Levihueque es en realidad, al menos desde la perspectiva de la administración colonial, un funcionario del Estado, tal cual se expresa en su sueldo incluido en el placarte del Ejército. ${ }^{44}$ Por otra parte, resulta factible suponer que al menos desde la perspectiva del mismo cacique, como sucede con otros de tierra adentro, la paga regular que se le asigna sea considerada como una suerte de retribución solidaria, en la línea de los intercambios tradicionales de la sociedad indígena. También se ha de recordar que Levihueque, al igual que otros caciques, ha entregado al menos a uno de sus hijos para que se eduque en el Colegio Carolino de naturales fundado a instancias del gobernador Jáuregui. ${ }^{45}$

42 Cuadro II, en León, 1999, 265.

43 Provisiones de empleos políticos y militares, 1785-1825, AGI, Chile, vol. 184, sin foliar.

44 Ignacio Levihueque, cacique gobernador de Santa Fe, figura regularmente entre 1775 y 1777 en las planillas donde se registra el pago mensual del sueldo a la tropa de la plaza de Los Ángeles. Cf. Cuentas de la Real Hacienda de Concepción, 1773-1777, AGI, Chile, vol. 398 , sin foliar.

45 Así se lee en las actas del parlamento de Tapihue (1774): "...les dijo últimamente que esperaba las pruebas de su reconocimiento al Rey, nuestro señor, no solo en su constante fidelidad, sino en la dedicación de sus hijos a la enseńanza política y cristiana, y que se los entregasen para poner en ejecución las piadosas intenciones de nuestro religioso soberano; en cuya inteligencia pasó el cacique gobernador don Ignacio Levihueque a manos 
En cuanto a la función de Ignacio Levihueque como dueño de la tierra de la reducción, esta situación es atestiguada usualmente en documentación posterior que busca justificar derechos de propiedad desde una perspectiva preponderantemente criolla. ${ }^{46} \mathrm{Y}$ es que la situación de la propiedad en Santa Fe es altamente compleja. Recordemos, una vez más, que las tierras que ocupa la reducción son el resultado de un fenómeno intrincado en el cual repercuten decisivamente los sucesos característicos del conflicto colonial fronterizo. Después de un período inicial de incorporación, al fin y al cabo fallida, de la población al sistema de encomienda, la población originaria de la Isla de la Laja resulta intensamente afectada por la caída vertiginosa de los índices demográficos, producto del desplazamiento, captura y muerte violenta. ${ }^{47}$ En particular, el gran alzamiento de mediados del siglo XVII representa un hito importante con visos indiscutibles de limpieza étnica: en todo el territorio han desaparecido las poblaciones formales indígenas (Ibarra, 1988 [1655]; Inostroza, 1998). A fines del siglo, en el marco de la reestructuración posterior al alzamiento, la administración colonial promueve la refundación de reducciones de indios amigos, todas ellas asociadas a presidios fronterizos. En este contexto se constituye Santa Fe, a partir de

de su señoría al hijo que le acompañaba, y ofrecieron los demás traer de sus reducciones los suyos...”. Correspondencia de los Presidentes de Chile, 1710-1775, AGI, Chile, vol. 189, sin foliar.

46 Filoteo Cuevas contra María Marilao por reivindicación de terrenos, 1842, ANH, JLA, leg. 2, pieza 8, 1-53v; María Marilao contra Antonio Calbuñir por reivindicación de terrenos, 1834, ANH, JLA, leg. 4, pieza 17, 1-38v.

47 Antes de 1566 se habían encomendado en cabeza de Alonso Galiano los indios de Tomeco y otras parcialidades en las zonas aledañas al Biobío. Cf. Gaspar de la Fuente: Juicio que sigue con Alonso de Figueroa, sobre mejor derecho a la encomienda de los indios de Tomeco, en la jurisdicción de San Bartolomé de Chillán, 1645 ANH, RA, vol. 1319, pieza 2, 103-124. Hacia 1605 , en el fuerte de Santa Fe de la Ribera, se mencionan cinco rehuas residentes en su jurisdicción: Puchangui (antiguo nombre con que se designaba al río Duqueco), Maquelvir, Panquegue, Cayogueno de los Llanos y una quinta no identificada. Cf. Alonso García-Ramón, gobernador Chile: Estado de la Guerra, 1605, AGI, Patronato, vol. 228, sin foliar. Al respecto ver también: Inostroza, 1998, 11-38, 59-94. un contingente atraído desde tierra adentro. ${ }^{48}$ Posteriormente cobra particular relevancia a través de los sucesos de $1723 .{ }^{49}$ En las mensuras de la Isla de la Laja, efectuadas como parte del proceso de fundación de la villa de Los Ángeles (1739-1741), su extensión territorial es sancionada oficialmente y en esta medida colonialmente legalizada: ${ }^{50}$ la reducción posee ocho mil cuadras de extensión.

¿Cuál es la situación de estas tierras? En teoría se trata de tierras comunales. ${ }^{51}$ Resulta extremadamente difícil definir el rol de cacique al respecto. Durante este período se observa, en la reducción de Arauco, cómo indios del común, bajo la anuencia de sus caciques, arriendan tierras a otros indígenas o a hispanos. ${ }^{52}$ Esta situación parece insinuar un paso importante hacia la privatización de la propiedad. En relación al papel que atañe al cacique en el control de la tierra, éste parece estar determinado por la noción del señorío sobre el territorio gracias a su función cacical. En general los textos explican la ocupación por parte de indios del común como una suerte de concesión o merced efectuada por el cacique. ${ }^{53}$ Es posible que esta idea esté

48 Cartas de Gobernadores: José de Garro, 7-I-1684, AGI, Chile, vol. 24, sin foliar.

49 El padre Diego de Amaya funda la misión de Santa Fe, 1724, ANH, Jesuitas, vol. 25, 89-89v.

50 El juez de mensuras del partido de Chillán, Antonio del Ribero, declaraba el 29 de noviembre de 1742: “...certifico en cuanto puedo y ha lugar en derecho de cómo en el término de tres años entendí en la mensura de tierras de la dicha Isla de La Laja y completas las mercedes que los señores gobernadores hicieron de ellas cuando les era facultativo, y las que comprende la reducción de indios de Santa Fe, hallé vacas la cantidad de cincuenta y dos mil, ciento y siete cuadras...”. Autos sobre la nueva población de la villa de Los Ángeles, 1743-1750, ANH, CG, vol. 689, pieza 7, 120 .

51 Así lo declara el informe del gobernador Benavides: "No tienen por repartimiento a familias, o a personas, las tierras; sino que libremente ocupa cada uno, y cultiva, lo que quiere, dentro de la pertenencia de la misión; usando regularmente de la muy precisa para cosechar el indispensable sustento". Correspondencia del presidente Ambrosio Benavides, 1784-1785, AGI, Chile, vol. 193, sin foliar.

52 Causa seguida contra Agustín de Marticorena, cura de Arauco, 1751, ANH, Jesuitas, vol. 76, pieza $37,133-137 \mathrm{v}$.

53 Así, por ejemplo, lo afirma Juan Cayuleo, indio de la reducción de Santa Fe, uno de los testigos en el pleito 
determinada por la praxis hispana de efectuar mercedes y la noción de las tierras vacantes y en general del suelo americano como propiedad real. En el caso de la praxis indígena es posible, si bien no he encontrado indicios de esta idea, que existiese la noción de que las tierras son propiedad ancestral del linaje del cacique en cuestión. Se ha de recordar en todo caso que la comunidad residente en Santa Fe es una entidad trasplantada desde tierra adentro y a la vez caracterizada por un sistema fluido de asentamiento y por una migración constante. En este contexto, la función del cacique gobernador parece estar determinada por su doble capacidad de acrecentar su propio prestigio y de ofrecer protección. La dimensión del prestigio aparece como requisito para lo segundo. El control de la tierra, que no la propiedad de la misma, resulta un medio fundamental de expresar y garantizar el bienestar de sus afiliados.

Al fin y al cabo, en Santa Fe, como en las otras reducciones en tierras de españoles, se evidencia el desarrollo de un sistema híbrido de propiedad, el cual conducirá inexorablemente a la enajenación de su identidad territorial con el arribo de la República. ${ }^{54}$

\section{Acceso de las familias "reducidas" al uso de la tierra}

A principios del siglo XIX, como producto de la transición del período colonial al republicano, con todas las ambigüedades e incoherencias que esto implica, se experimenta un proceso de disolución de la propiedad indígena en Santa Fe. Este proceso, al mismo tiempo que refleja la avidez y los mecanismos implementados por las élites criollas tardocoloniales para arrancar a los hijos de la tierra sus últimos derechos, evidencia las dinámicas particulares que han regido los modelos de propiedad en la reducción.

sobre las tierras de los Marilao en Santa Fe: “...que sabe y le consta que de los repartos que hizo dicho cacique de las tierras comprensivas en la reducción señaló dio posesión goce al dicho Marilao desde Negrete hasta las Cańas...”, María Marilao contra Antonio Calbuñir por reivindicación de terrenos, 1834, ANH, JLA, leg. 4, pieza 17, 9-9v.

54 En un fenómeno afín al que resulta posible observar en los pueblos de indios del Chile central. Cf. Silva, 1962, 198-203; Enríquez, 2011, 630, 638-640, 642-645.
Existen, para el contexto de este período, en el archivo judicial de Los Ángeles una serie de pleitos que se originaron a partir de este proceso. Todos ellos tienen en común la necesidad de esclarecer los derechos que asistían y justificaban el actuar tanto de compradores como vendedores. Uno de los más característicos es el que enfrentó a dos propietarios indígenas, María Marilao y Antonio Calbuñir, por el derecho a la propiedad ancestral de las tierras de las Cańas situadas junto a los llanos de Negrete. El pleito tiene su origen en la venta que ha llevado a cabo recientemente Calbuñir, una transacción que se enmarca dentro de la fiebre de ventas propias del decenio de 1830. El nudo argumentativo del pleito gira en torno a los derechos que reclaman ambas partes y que supuestamente se fundamentan en el parentesco que los une al emblemático cacique gobernador Ignacio Levihueque y a su hijo y sucesor Julián Leviluán. Así, por ejemplo, declara María Marilao en 1834:

[...] que por la línea paterna y heredad legítima nos corresponde un retazo de terreno demarcado según la costumbre inmemorial de los indígenas en la jurisdicción de Santa Fe lindante al cerro Negrete y del [roto] nombrado las Cańas, que en este paño mi padre Ignacio Marilao allí tuvo en posesión pacífica adquirida de su hermano cacique gobernador D. Julián Leviluán [...].55

Con el objeto de probar esta conexión genealógica y los privilegios que se asocian a ella ambas partes en contienda, ya que no pueden presentar ningún tipo de documentación escrita (mensuras, particiones, títulos de propiedad, cartas de venta, testamentos, etc.), solicitan interrogatorios de testigos que avalen sus pretensiones. A partir de estas deposiciones no resulta sencillo acceder a una noción sobre quién tenga la razón. María Marilao y sus testigos intentan probar que su padre, Ignacio Marilao, era pariente cercano de la estirpe gobernadora de Santa Fe y que dichos caciques habrían privilegiado a su familia con los terrenos en disputa. Por el contrario, Calbuñir y compartes alegan que Marilao fue un indio foráneo,

55 María Marilao contra Antonio Calbuñir por reivindicación de terrenos, 1834, ANH, JLA, leg. 4, pieza 17,2 . 
originario de Quechereguas, en la tierra adentro, y que solamente fue admitido de caridad en las tierras. Al mismo tiempo, Calbuñir intenta probar que es primo hermano de Leviluán y que su madre fue hermana de la mujer de Ignacio Levihueque.

En relación a la línea argumentativa que acentúa el papel propietario de los caciques, este pleito resulta de gran interés. Por otra parte, su valor fundamental radica en el hecho de expresar las dificultades inherentes a homologar las tradiciones indígenas con las hispanas. En este marco el documento más elocuente resulta ser un largo escrito presentado ante el juez de primera instancia en Los Ángeles, José Antonio Solano, y firmado por la propia María Marilao, quien hace alusión a su "ignorancia de aldeana e indígena” pero cuyo texto, probablemente, fue redactado por el procurador, Francisco Venegas:

[...] debo exponer, para ilustración de la materia, que don Ignacio Levihueque es el tronco fundamental de donde se originan todos los otros derechos. Bajo este supuesto (y como consta privado en autos) Leviluán le sucedió en autoridad y demás derechos; estos empleos se heredan entre ellos y son como unos señores feudales. Tanto sus hijos, como sus vasallos, componen una familia y los terrenos son comunes, sin más división social que sus posesiones. La autoridad del cacique aunque parece una democracia, sin embargo se les hace seńorío por los vasallos sobre la totalidad de terrenos, por la grande unión a sus ritos y costumbres que son sus leyes. Se prueba de esto, que sin embargo, que por sus respectivas posesiones adquieren dominio y señorío en sus goces, más en la aceptación general de reducción pertenece todo al cacique. No es así ahora en nuestros días que han entrado a regirse por nuestras leyes, entrando en nuestra comunión como chilenos. Estos ritos hacen notables algunas cosas un poco obscuras. Así que en aquellos tiempos unos tenían posesiones como vasallos y otros como descendientes pero todos habidos de un mismo origen: Levihueque. De aquí es que todos los vasallos han vendido en la autoridad sus goces sin contradicción alguna y con razón de estos principios nace que Calbuñir se haya querido hacer señor de mis terrenos y que algunos indios hayan declarado (quizá) que Leviluán era el dueño de Santa Fe por llamarse así los caciques de reducción... ${ }^{56}$

Este escrito presentado por María, bajo una aparente capa de erudición inusitada para el contexto fronterizo (haciendo referencia a categorías como el feudalismo, el vasallaje, la democracia y otros), busca retratar la situación a la cual se encontraría sometida la propiedad en tiempos coloniales y que ahora ("en nuestros días") habría cambiado radicalmente. Según este testimonio, lo característico del sistema vigente en la sociedad indígena sería el hecho de que en relación a los caciques "[...] tanto sus hijos, como sus vasallos, componen una familia y los terrenos son comunes, sin más división social que sus posesiones". Esta mancomunidad familiar, donde el cacique representa el origen y el garante de la propiedad sería el principio que asegura la ocupación de la tierra. Al fin y al cabo, los "ritos y costumbres" vienen a ser reemplazados, en el naciente sistema republicano, por las leyes de la nación y la suprema Constitución. Serán estas novedades, que ha traído consigo la independencia del modelo colonial, las que permitan, de ahora en más, la apropiación de las antiguas tierras de reducción en manos de una élite criolla fronteriza ávida de realizar su vocación de control sobre los sujetos y los territorios. ${ }^{57}$

56 María Marilao contra Antonio Calbuñir por reivindicación de terrenos, 1834, ANH, JLA, leg. 4, pieza 17, 31-31v.

57 Resulta altamente significativo que miembros de las élites políticas y económicas de la Frontera, que se proyectarán a nivel nacional, detenten importantes propiedades en la Isla de la Laja: Francisco Bulnes Prieto, la hacienda de Santa Fe; Manuel Bulnes Prieto, la hacienda de Las Canteras; Joaquín Prieto Vial, la hacienda de Boyelemu; Manuel Riquelme Meza, la hacienda de Curiche; Petrona Riquelme Meza, la hacienda de Duqueco. Todas ellas forman parte de las ocho propiedades más importantes en el departamento de La Laja en 1855. Cf. Ministerio de Hacienda 1855, 1-10. 


\section{Conclusiones}

El presente estudio etnohistórico ha buscado retratar, a partir de documentación inédita e intensamente fragmentada, la situación en que se encontraron, a lo largo del siglo XVIII, las familias mapuche asentadas en la reducción fronteriza de Santa Fe junto al río Biobío. Se trata de una situación altamente particular, determinada por la influencia de instituciones fronterizas coloniales sobre individuos y familias indígenas que se encontraron en la encrucijada de dos mundos en conflicto pero, al mismo tiempo, vinculados por múltiples intereses.

Quizás uno de los elementos más característicos en la articulación y desarrollo de estas unidades familiares fue la interacción compleja que se dio entre las familias indígenas y la frontera colonial, como espacio altamente singular. Entre las expresiones de esta interacción particular cabe mencionar, en primer lugar, la inestabilidad en el asentamiento. Familias de reducción fueron entes altamente fluidos en sus patrones de asentamiento $\mathrm{y}$, por lo tanto, en sus dinámicas identitarias, las cuales estuvieron determinadas por el acomodo de los individuos, muchos de ellos migrantes, a las novedosas situaciones vitales en que se encontraban. Estos fenómenos de adaptación, necesarios para sobrevivir en un medio no exento de conflictos y tensiones, de ninguna manera significaron el abandono de tradiciones y modos de vida de tipo ancestral. Esta realidad se ve retratada vivamente en informes y descripciones, material documental generado por la administración colonial, cuya finalidad resulta en una suerte de denuncia de la adhesión pertinaz al admapu entre los habitantes de estos espacios controlados por el sistema imperial.

Al mismo tiempo, la adaptación ocurrida en los espacios de reducción se vio reflejada en prácticas familiares híbridas, producto de una simbiosis altamente peculiar, inherente a un sistema que muchas veces reaccionó con ambigüedad y de manera oportunista, según la conveniencia propia a las coyunturas vigentes. Un primer aspecto, muy importante en el contexto de este artículo, fueron las modalidades matrimoniales vigentes en la reducción de Santa Fe en el debut del siglo XVIII, las cuales incluyeron el doble sistema de pagas a la usanza por el precio de la novia, al modo de la praxis en la "tierra adentro" (Boccara, 2009, pp. 63-82), y el matrimonio canónico cristiano efectuado in facie ecclesiae. Ambas modalidades fueron no solamente toleradas, sino que incluso promovidas por los mismos misioneros jesuitas, quienes en el caso de Juan Colerum y sus hijos proveyeron, a modo de préstamo, los recursos necesarios para efectuar las pagas por el precio de la novia. Un segundo fenómeno de hibridación se dio en el caso de la figura de los caciques gobernadores, personificados en Santa Fe por el emblemático Ignacio Levihueque. Este cacique viene a representar de manera patente una modalidad de autoridad familiar, al modo de los gülmen de la tierra, cuyo prestigio y prosperidad resultan garantes en su función mediadora entre las familias de la reducción y las autoridades coloniales. Por último, esta amalgama de representaciones encuentra a su vez una expresión en un modelo de propiedad familiar donde confluyen modalidades propias a los mundos amerindios y europeos. A fin de cuentas, este precario proyecto se vería defraudado, con el advenimiento de la República, la cual representará, en sí misma y en su visión del Estado, un triunfo del modelo colonial en su programación que propendía a la ocupación del espacio y el control sobre las personas.

\section{Agradecimientos}

Este artículo forma parte del proyecto FONDECYT regular No 1150614 (“Desnaturalización” y esclavitud indígena en fronteras americanas: la esclavitud de mapuches de la Araucanía y la de los indios de Nueva España, río de La Plata y Brasil (siglos XVI-XVII). El autor agradece especialmente las oportunas observaciones y propuestas llevadas a cabo por los pares evaluadores.

\section{Referencias citadas}

Boccara, G. (2009). Los Vencedores. Historia del Pueblo Mapuche en la Época Colonial (segunda edición). Santiago: Ocho Libros Editores / Universidad Católica del Norte.

Chuecas, I. (2017). Esclavitud indígena y economías familiares en el Chile del siglo XVII. En Valenzuela, J. (Ed.). América en diásporas. Esclavitudes y migraciones forzadas en Chile y otras regiones americanas (siglos XVI-XIX). 
Santiago: Pontificia Universidad Católica de Chile, Instituto de Historia / Red Columnaria / RIL Editores (en prensa).

Enríquez, L. (2011). La república chilena ante la cuestión indígena (1810-1830). Hispania Sacra, 63, 627-652.

Febrés, A. (1765). Arte de la lengua general del Reyno de Chile, con un diálogo chileno-hispano muy curioso... Lima: Calle de la Encarnación.

Gibson, C. (1984). Los aztecas bajo el dominio español (1519-1810). México D.F.: Siglo Veintiuno.

Guarda, G. (1968). Los caciques Gobernadores de Toltén. Boletin de la Academia Chilena de la Historia, 78, 43-68.

Hanisch, H. (1991). La esclavitud de los indios en el reino de Chile. Sus fuentes jurídicas. Prácticas y tráfico esclavista. Revista Chilena de Historia del Derecho, 14, 91-125.

Hanisch, W. (1981). Esclavitud y libertad de los indios de Chile: 1608-1696. Historia, 16, 5-65.

Hidalgo, J. (2004). Cacicazgos del sur occidental andino: origen y evolución colonial, en Historia Andina en Chile I. Santiago: Editorial Universitaria, 471-477.

Hidalgo, J., y Castro, N. (2004). El liderazgo étnico en Atacama, Altos de Arica, Tacna y Tarata (siglo XVIII). Chungara. Revista de Antropología Chilena, 36, volumen especial 2, 799-811.

Ibarra, A. ([1655] 1988). Relación de don Antonio de Ibarra al virrey Conde de Alba sobre los acaecimientos de Chile en 1655. En Anadón, J. Historiografía literaria de América colonial (pp. 321-392). Santiago: Ediciones Universidad Católica de Chile.

Inostroza, I. (1998). Historia de Concepción. Organización social y economía agraria, 1600-1650. Temuco: Ediciones Universidad de La Frontera.

Jurado, M. C. (2014). “Descendientes de los primeros”. Las probanzas de méritos y servicios y la genealogía cacical. Audiencia de Charcas, 1574-1719. Revista de Indias, 74, 387-398.

León, L. (1999). Apogeo y ocaso del Toqui Ayllapangui de Malleco, Chile. 1769-1776. Santiago: LOM / Dibam, Centro de Investigaciones Diego Barros Arana.
López Z., T. (1923 [Madrid, 1777]). Mapa de una parte de Chile, que comprehende el terreno donde pasaron los famosos hechos entre Españoles y Araucanos. Santiago: Mapoteca Americana de Don José Toribio Medina, Taller de la Inspección de Geografía.

Lucaioli, C. (2010). Los espacios de frontera en el Chaco desde la conquista hasta mediados del siglo XVIII. En Lucaioli, C. P., y Nacuzzi, L. R. (Comps.). Fronteras, Espacios de interacción en las tierras bajas del sur de América. Buenos Aires: Sociedad Argentina de Antropología, 21-68.

Ministerio de Hacienda (Ed.). (1855). Estado que manifiesta la renta agrícola de los fundos rústicos que comprende el impuesto anual establecido en la sustitución del diezmo por la lei de 25 de Octubre de 1853, vol. 2. Provincia de Arauco, Departamento de la Laja. Valparaíso: Imprenta del Diario.

Obregón Iturra, J. (2010). Para acabar con los "indios enemigos"... y también con los "amigos". Los mapuchearaucanos ante las concepciones hispanas de alianzas y antagonismos (Chile, 1670-1673). En Araya E., A., y Valenzuela M., J. (Eds.). América colonial. Denominaciones, clasificaciones e identidades (pp. 173-199). Santiago: RIL Editores.

Ruiz-Esquide, A. (1993). Los indios amigos en la frontera araucana. Santiago: Dibam, Centro de Investigaciones Diego Barros Arana.

Silva, F. (1962). Tierras y pueblos de indios en el Reino de Chile. Esquema histórico-jurídico. Estudios de Historia del Derecho Chileno núm. 7. Santiago: Ediciones de la Universidad Católica de Chile, Facultad de Ciencias Jurídicas, Políticas y Sociales.

Villalobos, S. (1989). Los Pehuenches en la vida fronteriza. Santiago: Ediciones Universidad Católica de Chile.

Wright, P. Colonización del espacio, la palabra y el cuerpo en el Chaco Argentino. Horizontes Antropológicos, 19, 137-152.

Zavala, J. M. (Ed.) (2015). Los parlamentos Hispano-Mapuches, 1593-1803: Textos fundamentales. Temuco: Ediciones Universidad Católica de Temuco. 


\section{Documentación manuscrita}

Archivo General de Indias (Sevilla), Audiencia de Chile (AGI, Chile), vols. 13, 21, 24, 25, 46, 138, 184, 189, 193, $199,204,398$ y 436.

Archivo General de Indias (Sevilla), Patronato Real (AGI, Patronato), vol. 228.

Archivo Histórico Nacional (Madrid), Consejo de Indias (AHNM, Consejo de Indias), vol. 20419.

Archivo Nacional Histórico (Santiago de Chile), Archivo Fernández Larraín (ANH, Fernández Larraín), vol. 71.

Archivo Nacional Histórico (Santiago de Chile), Capitanía General (ANH, CG), vols. 295, 508 y 689

Archivo Nacional Histórico (Santiago de Chile), Judicial de los Ángeles (ANH, JLA), legs. 2 y 4.

Archivo Nacional Histórico (Santiago de Chile), Junta de Temporalidades de la Compañía de Jesús (ANH, Jesuitas), vol. 25, 64, 73, 76 y 94.

Archivo Nacional Histórico (Santiago de Chile), Notarios de los Ángeles (ANH, NLA), vol. 2.

Archivo Nacional Histórico (Santiago de Chile), Real Audiencia (ANH, RA) vol. 1319.

Archivo de la Orden de San Francisco, Fondo Chillán (AOSF, Chillán), Asuntos Varios (1787-1790), vol. 6.

Archivo Romano de la Compañía de Jesús (Roma), Chile (ARCJ, Chile), vol. 4. 